\title{
Oviposition Behaviour of Cleruchoides noackae (Hymenoptera: Mymaridae) in the Laboratory
}

\author{
Jucelaine Haas ${ }^{1}$, Leonardo Rodrigues Barbosa ${ }^{2}$, Michele Potrich ${ }^{1}$, \\ Everton Ricardi Lozano ${ }^{1}$, Sérgio Miguel Mazaro ${ }^{1}$
}

${ }^{1}$ Coordenação de Ciências Biológicas, Universidade Tecnológica Federal do Paraná - UTFPR, Dois Vizinhos/PR, Brasil ${ }^{2}$ Embrapa Florestas, Colombo/PR, Brasil

\begin{abstract}
Thaumastocoris peregrinus has become a major pest in eucalyptus. The most promising control method is the use of the parasitoid, Cleruchoides noackae, but little is known about its biology. Thus, the aim of this study was to investigate the oviposition behaviour of C. noackae in T. peregrinus eggs laid on strips of paper towel in the laboratory. 12 copulated females were placed in a plastic petri dish containing five T. peregrinus eggs and their behaviour was observed for $30 \mathrm{~min} / \mathrm{female}$. Several behavioural events were performed: searching for the host, host evaluation, insertion of the ovipositor, internal recognition and oviposition. Time elapsed between the insertion of the ovipositor and its removal varied from two to ten minutes. Learning more about C. noackae biology is very important to understand the dynamics between the parasitoid and its host, aiming at its biological control.
\end{abstract}

Keywords: reproductive biology, bronze bug, parasitoid. 
Chalcidoidea has been described as the most successful group used in applied biological control. Currently, about 22,000 species have been described, but it is suggested that there may be over 500,000 existing species (Noyes, 2003). Among these are members of Mymaridae, called fairyflies; these primarily parasitize eggs of other insects. These are very small, ranging from 0.2 to $4.0 \mathrm{~mm}$ in length (Yoshimoto, 1990) and possess delicate wings with long fringes (Huber \& Noyes, 2013).

Cleruchoides noackae (Hymenoptera: Mymaridae) is a solitary egg parasitoid first described by Lin \& Huber and has been found parasitizing eggs of Thaumastocoris peregrinus Carpintero and Dellapé (Hemiptera: Thaumastocoridae) in Eucalyptus trees in Australia (Lin et al., 2007).

Thaumastocoris peregrinus is a native Australian eucalyptus sap-feeding insect which has become invasive worldwide. It causes chlorosis followed by bronzing of the leaves, and heavy infestations can lead to defoliation. Currently, it attacks approximately 43 Eucalyptus species and hybrids, and it is spreading rapidly (Carpintero \& Dellapé 2006; Nadel et al., 2012; Montemayor et al., 2015). Unfortunately, there is no effective control method yet ascertained.

The egg parasitoid C. noackae has only been reported using species within the Thaumastocorinae group (Lin et al., 2007; Nadel et al., 2010). Therefore, since its detection, $C$. noackae has been introduced into both South America and South Africa in an attempt to control the population of this forest pest (Nadel \& Noack, 2012).

Despite being employed as a promising biological control agent, little is known about $C$. noackae biology or its interaction with $T$. peregrinus, especially regarding its oviposition behaviour (Nadel et al., 2012; Beltramin, 2013; Mutitu et al., 2013). Moreover, the little research published considers the parasitoid behaviour with eggs laid of T. peregrinus on eucalyptus leaves (Mutitu et al., 2013). Therefore, the aim of this study was to investigate the oviposition behaviour of $C$. noackae in T. peregrinus eggs laid on strips of paper towel in the laboratory.

The experiment was conducted at the Entomology Laboratory at Embrapa Florestas in Colombo, Brazil, where T. peregrinus and C. noackae colonies began to be maintained in 2009 and 2012, respectively. For the experiments, parasitoids from the $21^{\text {st }}$ and $22^{\text {nd }}$ generations reared in the lab were used. The rearing conditions for both insects were as described by Beltramin (2013).

Thaumastocoris peregrinus nymphs and adults were reared in Eucalyptus benthamii Maiden et Cambage branches with fully expanded leaves $\left(23 \pm 2{ }^{\circ} \mathrm{C}, 60 \%\right.$ $\mathrm{RH}$ and $12 \mathrm{~h}$ photoperiod) and strips of paper towel were distributed along the leaves for the hemipterans oviposition. These strips were replaced daily in order to obtain fresh eggs with less than 24 hours, which were used in the experiment.

Cleruchoides noackae was maintained in polystyrene flasks ( $7.0 \mathrm{~cm}$ in length and $3.0 \mathrm{~cm}$ in diameter), the lids of which were perforated and covered with a fine voile mesh to permit aeration. For their feeding, strips of filter paper $(0.5 \mathrm{~cm} \times 5 \mathrm{~cm})$ with a $50 \%$ honey solution were added inside the tubes. T. peregrinus eggs were given/replaced daily for female oviposition. Both fertilized eggs and C. noackae adults were maintained in a germination chamber $\left(22 \pm 2{ }^{\circ} \mathrm{C}, 60 \pm 10 \% \mathrm{RH}\right.$ and $12 \mathrm{~h}$ photoperiod). For the initial experiment, the polystyrene flasks were checked every hour in order to find recipients where only females emerged, in order to be certain they had not copulated.

A previous experiment was conducted with non-copulated females and males of $C$. noackae $(n=5)$. One male followed by one virgin female were placed inside a plastic petri dish $(35 \mathrm{~mm} \times 10 \mathrm{~mm})$ with five T. peregrinus eggs adhered to a $1 \mathrm{~cm}^{2}$ piece of paper towel in the centre and a strip of filter paper $(0.5 \mathrm{~cm} \times 1 \mathrm{~cm})$ in a corner of the dish. The time was recorded and the insects were observed for a period of 30 minutes/couple in order to verify their mating behaviour, whether they would copulate or feed and how long it took them to perform these activities.

In the main experiment, females emerged within less than three hours were left inside polystyrene flasks with males (one couple per tube) with honey for 20 hours to guarantee that copulation would occur $\left(22 \pm 2{ }^{\circ} \mathrm{C}\right.$, $60 \pm 10 \% \mathrm{RH}$ and $12 \mathrm{~h}$ photoperiod). Afterwards, a parasitoid female was placed in a plastic petri dish under the same conditions as the previous test except for the absence of the male. In total, 12 copulated females were observed for $30 \mathrm{~min} /$ female and their oviposition behaviour was observed.

In the pre-test, copulation was not observed within 30 minutes in any of the couples evaluated. Both males and females explored the petri dish during the evaluation 
period with rapid antennal movements. Even after they came into close contact, both C. noackae continued to explore. Therefore, since no mating behaviour was sighted, the experiment was abandoned. Mutitu et al. (2013), reported that parasitoid mating occurred within 2-5 $s$ after the male encountered the females.

In the main experiment, $C$. noackae presented a series of behavioural events: walking (searching for the host), host evaluation (parasitoid walking on the host, making contact with the antennae and tarsomeres), insertion of the ovipositor, and internal recognition and oviposition (Vinson, 1976). As soon as the females were liberated, the time exploring the environment before stopping and evaluating an egg varied from nine to 436 seconds. Two copulated females explored the environment for 15 minutes, not pausing on either the eggs or the honey. Only one C. noackae refused the first egg, while all the others, within less than 35 seconds of tapping the first egg with their antennae, inserted the ovipositor for probing followed by oviposition. Right after withdrawing it, the parasitoid drummed the host rapidly again with its antennae and searched for the next egg. During oviposition, the time elapsed between insertion and removal of the ovipositor was between two to ten minutes. This behaviour was repeated five or six times for each C. noackae among the five eggs, sometimes returning to the same egg for oviposition.

Oviposition often takes place right after the encounter with the host as well as the parasitoid behaviour of tapping the eggs with their antennae before and after oviposition but repeated oviposition in the same egg was rare (Mutitu et al. 2013). However, this may have occurred due to the large number of eggs offered to C. noackae, 20 per female, while in the test reported here there was only five eggs for her to choose from. Just once, one female probed the egg and did not accept it. Additionally, only one female chose to feed first instead of going to the bronze bug eggs. None of the others fed during the test. This behavioural component indicates the biological need to perpetuate the species and indicates a useful trait for biological control.

Searching and oviposition behaviour of two species of Anaphes (Hymenoptera: Mymaridae), including ovipositor positioning while the female is on the egg, abdominal vibrations, drilling and abdominal contractions has been described by Baaren et al. (1995).
All these behavioural components were found during the test with C. noackae.

Knowledge of C. noackae biology including its oviposition behaviour such as described in this study is very important to understand the dynamics between this parasitoid and its host, T. peregrinus, when seeking its biological control.

\section{ACKNOWLEDGEMENTS}

The authors thank CNPq for the financial support.

\section{SUBMISSION STATUS}

Received: 22 may, 2015

Accepted: 26 june, 2016

\section{CORRESPONDENCE TO}

\section{Jucelaine Haas}

Coordenação de Ciências Biológicas, Universidade Tecnológica Federal do Paraná - UTFPR, Estrada para Boa Esperança, Km 4, CEP 85660-000, Dois Vizinhos, PR, Brasil e-mail: jucelainehaas@gmail.com

\section{REFERENCES}

Baaren J van, Nénon J-P, Boivin G. Comparison of oviposition behaviour of solitary and gregarious parasitoids (Hymenoptera: Mymaridae). Journal of Insect Behavior 1995; 8(5): 671-686. http://dx.doi.org/10.1007/BF01997237.

Beltramin FS. Estratégias para o controle biológico de Thaumastocoris peregrinus Carpintero \& Dellapé, 2006 (Heteroptera: Thaumastocoridae) [monografia]. Curitiba: Universidade Federal do Paraná; 2013.

Carpintero DL, Dellapé PM. A new species of Thaumastocoris Kirkaldy from Argentina (Heteroptera: Thaumastocoridae: Thaumastocorinae). Zootaxa 2006; 1228: 61-68.

Huber JT, Noyes JS. A new genus and species of fairy fly, Tinkerbella nana (Hymenoptera, Mymaridae), with comments on its sister genus Kikiki, and discussion on small size limits in arthropods. Journal of Hymenoptera Research 2013; 32: 17-44. http://dx.doi.org/10.3897/ jhr.32.4663.

Lin N-Q, Huber JT, Salle J. The Australian Genera of Mymaridae (Hymenoptera: Chalcidoidea). Zootaxa 2007; 1596: 1-111.

Montemayor SI, Dellapé PM, Melo MC. Geographical distribution modelling of the bronze bug: a worldwide 
invasion. Agricultural and Forest Entomology 2015; 17(2): 129-137. http://dx.doi.org/10.1111/afe.12088.

Mutitu EK, Garnas JR, Hurley BP, Wingfield MJ, Harney M, Bush SJ et al. Biology and rearing of Cleruchoides noackae (Hymenoptera: Mymaridae), an egg parasitoid for the biological control of Thaumastocoris peregrinus (Hemiptera: Thaumastocoridae). Journal of Economic Entomology 2013; 106(5): 1979-1985. PMid:24224238. http://dx.doi.org/10.1603/EC13135.

Nadel R, Noack A. Current understanding of the biology of Thaumastocoris peregrinus in the quest for a management strategy. International Journal of Pest Management 2012; 58(3): 257-266. http://dx.doi.org/10.1080/09670874.201 2.659228 .

Nadel RL, Slippers B, Scholes MC, Lawson SA, Noack AE, Wilcken CF et al. DNA bar-coding reveals sources and patterns of Thaumastocoris peregrinus invasions in South Africa and South America. Biological Invasions 2010; 12(5): 1067-1077. http://dx.doi.org/10.1007/s10530-009-9524-2.
Nadel RL, Wingfield MJ, Scholes MC, Lawson SA, Noack AE, Neser S et al. Mithochondrial DNA diversity of Cleruchoides noackae (Hymenoptera: Mymaridae): a potential biological control agent for Thaumastocoris peregrinus (Hemiptera: Thaumastocoridae). BioControl 2012; 57(3): 397-404. http://dx.doi.org/10.1007/s10526011-9409-z.

Noyes JS. Universal Chalcidoidea Database - About chalcidoids [online]. London: Natural History Museum; 2003 [cited 2014 abr 6]. Available from: http://www.nhm. ac.uk/research-curation/research/projects/chalcidoids/ introduction.html

Vinson SB. Host selection by insect parasitoids. Annual Review of Entomology 1976; 21(1): 109-133. http://dx.doi. org/10.1146/annurev.en.21.010176.000545.

Yoshimoto CM. A review of the genera of New World Mymaridae (Hymenoptera: Chalcidoidea). Gainsville: Sandhill Crane Press Inc.; 1990. (Flora \& Fauna Handbook; no. 7). 